\title{
How SMART Are Your Patients Goals?
}

David Stonehouse is a Lecturer with the School of Nursing and Midwifery at Queens University Belfast.

\section{Abstract.}

As a second follow up to 'understanding the nursing process' (Stonehouse, 2017), this article examines the importance of goal setting within the planning stage of the nursing process. The acronym SMART will be explored to help guide the support worker in making sure their patients have the correct goals in place. Relevant sections of The Code of Conduct for Healthcare Support Workers and Adult Social Care Workers in England (Skills for Care and Skills for Health, 2013) will be highlighted. Once appropriate and attainable goals are set the support worker can then deliver quality care to meet these goals in partnership with their patients.

Key Words: Goals, Nursing Process, Planning, SMART, Support Workers.

\section{Introduction}

The nursing process, comprising initially four (Yura and Walsh, 1967) and then five (American Nurses Association, 2018) key stages, is a decision making approach (Yildirim and Ozkahraman, 2011) which assists in the delivery of quality care. After the first two stages of assessment and nursing diagnosis, comes the planning stage where goals are set. Support workers will be key in delivering interventions designed to achieve these goals. Therefore support workers need to understand and be involved in their planning, implementation and evaluation.

\section{Code Words.}

Within The Code of Conduct for Healthcare Support Workers and Adult Social Care Workers in England (Skills for Care and Skills for Health, 2013) there are a number of sections which are relevant in relation to goal setting. Firstly section 1.3 states that the support worker must "be able to justify and be accountable for your actions or your omissions." As support workers you will be the one delivering the hands on care. If you do not know which goals are trying to be achieved, how can you rightly justify your actions? If goals have been badly planned and are unachievable clearly implementation should not be attempted and the planning stage of the nursing process needs to be repeated. 
Section 2.3 states support workers must "put the needs, goals and aspirations of people who use health and care services first." Has the patient's wishes been taken into account when goals have been set? Have patient's been equal partners in the planning process? Section 3.4 goes on to state that you must "work openly and cooperatively with people who use health and care services and their families and carers and treat them with respect" Through understanding how and why goals have been set will enable you to work in an open and cooperative way with your patients, respecting their wishes regarding their care.

Section 4.3 states "always explain and discuss the care, support or procedure you intend to carry out with the person and only continue if they give valid consent." How can you truly discuss and explain the care if you do not understand the goal that has been planned? Will the patients consent be valid if you have not been able to explain this clearly to them? Therefore to meet The Code of Conduct for Healthcare Support Workers and Adult Social Care Workers in England (Skills for Care and Skills for Health, 2013) and to give safe care of the highest quality support workers need to understand and be involved in goal setting.

Finally, through doing this, through reading this article and reflecting upon learning from it and applying it to your practice you will be achieving Section 6.2 which states you must "participate in continuing professional development to achieve the competence required for your role."

\section{Planning}

As identified by Hogston (2011) there are two stages to the planning phase, goal setting and then the identification of actions to meet those goals. Goals should be both short term and long term in nature. A number of goals may be set by the health professional, for instance to reduce a patients temperature, or to control a patients pain levels. Other goals will be led and set by the patient themselves. These may be around changing life style behaviours, for instance giving up smoking or increasing exercise levels. However all goals need to be discussed with and accepted by the patient wherever possible.

The acronym S.M.A.R.T. was first used in 1981 by Doran who invented it to assist managers in setting organisational objectives. SMART stands for Specific, Measurable, Assignable/Attainable/Achievable, Relevant/Realistic, and Timed (Doran, 1981, Upton and Thirlaway, 2010). All five parts are interconnected and linked together and must therefore be taken as a whole for the goal to be SMART.

The first part of the acronym asserts that the goal must be Specific. This means that it is clearly defined and unambiguous. Everyone knows what is to be achieved. So for example Mr Smith will mobilise six hours after surgery.

For you to know that a goal has been achieved, either fully or partially, the goal needs to be Measurable in some way. This could be through observation of your 
patient, asking them directly, or through the recording of clinical signs and symptoms. A goal which is not being achieved may either not be completely SMART or the interventions put in place to achieve it may not be appropriate.

In Doran's (1981) original SMART acronym A stood for Assignable. This meant clearly identifying the person who is going to be responsible for achieving the goal. This could be the nurse, support worker, carer or patient themselves. Today the $\mathbf{A}$ is commonly taken to stand for Attainable or Achievable (Lee, 2010, Furze, 2015). For a patient with a low grade pyrexia, it should be achievable for this to be reduced within normal limits within a reasonable time frame. However a goal for a patient to successfully give up smoking, for someone who clearly does not wish to do so, no matter how well intentioned, would not be achievable.

Next consider if the planned goal is Relevant and Realistic. Can the patient achieve this goal? Conneeley (2004) identified that if a patient's goal is clearly unrealistic given their prognosis or diagnosis then this needs to be addressed with them. This may require counselling skills on the part of the healthcare professional so the patient does not feel disempowered. By focusing on more short term attainable goals expectations can be discussed and managed. The support worker must also act as an advocate for their patients and question when other health care professionals plan and promote unrealistic goals.

Lastly, is the goal Timed? By this it is meant has a time scale been set for the achievement of the goal. Having a clear time frame gives both the patient and support worker a target to aim towards (Upton and Thirlaway, 2010). This could be short term, within the next few hours, or long term, within six months' time or longer. Again, is it realistic for the patient to achieve this goal within that time frame? Barrett et al (2009) state it is often better to have short term goals rather than long term ones as this can help maintain the morale and motivation of the patient.

Once the SMART goal has been set the nursing process continues. Interventions to achieve that goal need to be identified and implemented. Once implemented evaluation occurs to check that the care delivered has been successful in achieving the goals. If not, then the goals may need to be changed or different interventions adopted.

\section{Conclusion.}

So to conclude, this article has highlighted the importance that goal setting should be SMART. By implementing care designed to meet these goals will ensure that quality care is delivered. Support workers play an important role in delivering care and therefore need to understand how and why goals have been planned. Patients need to be involved as equal partners in setting their own goals as well as being involved in goal setting by healthcare professionals. Through this patients will become true partners in their care. 
Key Points:

1. Through the use of SMART goals the planning stage of the nursing process will be successful.

2. Goals should be set in collaboration with the patient.

3. The support worker must question unrealistic goals, thereby acting as an advocate for their patients.

4. Short term goals should be used to help maintain the morale and motivation of patients.

5. Support workers are key to the achievement of SMART goals.

\section{$\underline{\text { References: }}$}

American Nurses Association (2018) The Nursing Process.

http://www.nursingworld.org/EspeciallyForYou/What-is-Nursing/Tools-You-

Need/Thenursingprocess.html (accessed 15 February 2018)

Barrett D, Wilson B, Woollands, A. (2009) Care Planning: A guide for Nurses.

Pearson Education: London

Conneeley A L (2004) Interdisciplinary Collaborative Goal Planning in a Post-acute Neurological Setting: A Qualitative Study. British Journal of Occupational Therapy 67(6): 248-255

Doran G T (1981) There's a S.M.A.R.T. Way to write Management's Goals and Objectives. Management Review 70(11): 35-36

Furze G (2015) Goal Setting: A Key Skill for Person-centred Care. Practice Nursing 26(5): 241-244

Hogston R (2011) Managing Nursing Care. In: Foundations of Nursing Practice: Themes, Concepts and Frameworks. $4^{\text {th }}$ edn. Palgrave Macmillan: London. 2-21

Lee K P W (2010) Planning for Success: Setting SMART Goals for Study. British Journal of Midwifery 18(11): 744-746

Skills for Care and Skills for Health (2013) Code of Conduct for Healthcare Support Workers and Adult Social Care Workers in England.

http://www.skillsforhealth.org.uk/images/services/code-ofconduct/Code\%20of\%20Conduct\%20Healthcare\%20Support.pdf (accessed 15 February 2018)

Stonehouse D (2017) Understanding the Nursing Process. British Journal of Healthcare Assistants 11(8): 387-391 
Upton D, Thirlaway K (2010) Promoting Healthy Behaviour: A Practical Guide for Nurses and Healthcare Professionals. Pearson: London

Yildirim B Ozkahraman S (2011) Critical Thinking in Nursing Process and Education. Int J Soc Sci Res 1(13): 257-262

Yura H, Walsh M (1967) The Nursing Process. Appleton Century Crofts, Norwalk 